Res Publica. Revista de Historia de las Ideas Políticas ISSN-e: 1989-6115

\title{
Repensar el poder desde Claude Lefort: una propuesta interpretativa*
}

\author{
Edgar Straehle**
}

Recibido: 14 de noviembre de 2018 / Aceptado: 10 de junio de 2019

Resumen. En este artículo se expone una concepción del poder que parte de las reflexiones de Claude Lefort y que reivindica su dimensión simbólica. Para ello, primero se aborda la descripción que Clifford Geertz hizo de la antigua sociedad política balinesa como ejemplificación radical de un "poder estético". Luego se continúa con las reflexiones de Lefort en torno al carácter simbólico del poder, cómo estas permiten entenderlo dentro de un espacio en permanente disputa y como un concepto que no debe ser reducido a la coerción o la violencia ni que tampoco debe ser exclusivamente analizado desde una perspectiva material. Para ello, se abordan las tres figuras del poder que, según el análisis de Lefort, se corresponden a tres tipos de formas políticas distintas: el antiguo régimen, el totalitarismo y la democracia.

Palabras clave: Claude Lefort; Clifford Geertz; Poder; Democracia; Totalitarismo.

\section{[en] Rethinking Power from the Perspective of Claude Lefort: an Interpretive Approach}

\begin{abstract}
In this article I develop a different interpretation of power that derives from Claude Lefort's works and that highlights the relevance of its symbolic dimension. To this purpose, I start by examining Clifford Geertz's analysis of the Balinese ancient political society as the most radical example of a kind of "aesthetic power". Later, I describe and comment Lefort's remarks on the symbolic character of power and how these reflections show that power is always in dispute; furthermore, why power should not be merely identified with coercion or violence and exclusively analyzed from a material perspective either. To this purpose, I will examine three faces of power that, according to Lefort, correspond to three different political forms: Ancien Régime, totalitarianism and democracy.
\end{abstract}

Keywords: Claude Lefort; Clifford Geertz; Power; Democracy; Totalitarianism.

Sumario: 1. Introducción. 2. Clifford Geertz y el Estado-teatro de Bali. 3. Claude Lefort y la dimensión simbólica del poder. 4. Del poder del Antiguo Régimen al poder totalitario. 5. El lugar del vacío del poder en la democracia

Cómo citar: Straehle, E. (2019). Repensar el poder desde Claude Lefort: una propuesta interpretativa, en Res Publica 22.2, 477-494.

\footnotetext{
* Este trabajo se enmarca dentro de los proyectos de investigación "La transmisión desde el pensamiento filosófico femenino" (FFI2015-63828-P, MINECO/FEDER, UE) y GRC "Creació i pensament de les dones" (2017 SGR 588).

** Universidad de Barcelona edgarstraehle@gmail.com
} 


\section{Introducción}

El concepto de poder sigue siendo hoy en día uno de los más estudiados y, al mismo tiempo, uno de los más enigmáticos y escurridizos. No pocas veces sigue siendo considerado como el fenómeno central de la política y no debe extrañar por ello que un buen número de pensadores lo hayan examinado con detenimiento y lo hayan repensado de una manera personal, aportando nuevos matices y ángulos desde los que observarlo. A su vez, eso explica que no tengamos una sino múltiples interpretaciones de lo que se oculta detrás de esta palabra, algunas de ellas contradictorias o incompatibles entre sí. Hoy en día, pues, ya no hay solamente una sino una pluralidad de conceptos de poder.

En no pocos casos, además, la centralidad del concepto de poder se revela por el simple hecho de que su reinterpretación suele ir conectada a una reinterpretación general de lo que se entiende por política. Sin ir más lejos, pensemos en ejemplos conocidos como los representados por Michel Foucault y Hannah Arendt y en el rol que este concepto desempeña en las obras de cada uno de ellos. Repensar el poder no consiste únicamente en abordar el significado de una palabra sino, con frecuencia, en replantearse el significado mismo o hasta dónde llegan los límites de lo que se entiende por política, sea de una manera directa o de una más indirecta u oblicua.

En este texto tengo la intención de retomar las contribuciones de Claude Lefort en torno a la cuestión del poder bajo esta perspectiva y, con ello, de reflexionar acerca de cómo inciden esas apreciaciones suyas en la comprensión de la política. Este trabajo consiste asimismo en una reivindicación de su obra y de unas reflexiones sobre el poder que tienen la virtud de dirigir la mirada sobre ciertos de sus aspectos que hasta el momento no han sido lo suficientemente resaltados.

\section{Clifford Geertz y el Estado-teatro de Bali}

Uno de los textos más sugerentes y complejos a la hora de estudiar qué es el poder es Negara, una obra que escribió Clifford Geertz en 1980 sobre el gobierno de los antiguos reyes de Bali y una investigación en la que se entrecruzan la antropología, la historia y la filosofía. Además, es un texto que puede servirnos como una puerta de entrada para la comprensión lefortiana del poder.

Uno de los leitmotivs de Negara, palabra que significa "ciudad" pero también "reino", "poder", "gobierno" o "cultura" en sánscrito", gira en torno a la íntima conexión entre el poder y su dimensión escénica, razón por la que Geertz se refiere a Bali como lo que denomina un "Estado-teatro". Ahora bien, la cuestión no reside solamente en destacar la dimensión simbólica y teatral del poder, algo ya sabido desde hace mucho tiempo y que podemos colegir tras echar un simple vistazo a los rituales, los desfiles, los discursos, las imágenes, las canciones, los monumentos, los museos, las monedas y otras formas de propaganda más explícitas o más subliminales de las grandes civilizaciones del pasado o la mayoría de sociedades del presente. Los campos por los que se puede diseminar la vertiente más estética y simbólica del poder son muy numerosos y en ellos se entremezclan sin cesar lo material y lo discursivo.

C. Geertz, Negara: el estado-teatro en el Bali del siglo XIX, Barcelona, Paidós, 2000, p. 16. 
Frente a otros $\operatorname{casos}^{2}$, lo que proporciona el de Bali, siempre según el análisis de Geertz, es un ejemplo extremo, una extraña radicalización que, al menos en apariencia, rompe con no pocos esquemas de la política y de la comprensión tradicional del poder: en su seno, la dimensión ceremonial o semiótica adquiere un peso tan decisivo que llega a confundirse con la esencia misma de lo que constituye el gobierno. Lo estético no es solo una instancia de legitimación ni una manera de presentarse o de publicitar su ideario sino, por así decir, la misma realidad gubernamental en sí. De ahí que este antropólogo apuntara que

las estupendas incineraciones, empastes dentales, dedicaciones de templos, peregrinaciones y sacrificios sangrientos - que movilizaban a cientos, incluso a miles, de individuos y suponían el gasto de grandes cantidades de riqueza-, no eran medios para fines políticos: eran fines en sí mismos, eran aquello para lo que servía el Estado (...). Los rituales de masas no eran un invento para apuntalar el Estado, sino que más bien el Estado, en su último aliento, era un invento para la promoción de los rituales de masas. El poder servía a la pompa, no la pompa al poder ${ }^{3}$.

En Bali se habría producido una suerte de inversión. Aquello que, al menos desde la perspectiva occidental, se suele ver como un medio del poder se convierte en su fin. Al mismo tiempo, muchos de los que se nos aparecen como fines pasarían a ser medios según la cosmovisión balinesa. Por eso Geertz indica que en Bali hay una obsesión por el rango ${ }^{4}$ o que el ceremonialismo es la fuerza conductora de su política. El poder, a menudo asociado a lo oscuro, lo misterioso y lo secreto (como con los clásicos arcana imperii) pasa a entenderse aquí desde su plena apariencia y visibilidad. En este caso, el poder no se disfraza bajo unos ropajes que disimulan su rostro verdadero, sino que se muestra y hace visible. Eso explica que en el antiguo reino de Bali hubiera, para nosotros, una difícilmente comprensible estética política; una estética hasta cierto punto pura, sin un trasfondo o profundidad que la explique desde "atrás". Lo "real" no sería lo profundo y lo escondido, algo fuera de nuestra vista, sino lo superficial y perspicuo. Si por lo general es lo aparente lo que se explica desde lo oculto, aquí ocurriría al revés.

A partir de lo descrito, se podría afirmar que en Bali la ontología del gobierno se hallaría en las apariencias, algo que acerca este análisis a la comprensión lefortiana de la política. Para Geertz la misma vida de la corte no es solo el núcleo, el motor o el pivote del Estado, tampoco lo refleja o reproduce de algún modo, sino que tiene una dimensión constituyente y, más aún, es el mismo Estado en sís. Geertz describe sus ceremoniales como un teatro metafísico que no solo expresa la naturaleza última de la realidad, pues también modela "las condiciones de vida existentes de tal manera que result[en] consonantes con dicha realidad; es decir, teatro para presentar una on-

Pensemos por ejemplo en los diferentes usos de la memoria de las sociedades antiguas, analizados con maestría por Jan Assmann; asimismo en el célebre texto que se transmite en ocasión de la oración fúnebre de Pericles y en el magistral estudio que Nicole Loraux hizo del logos epitaphiós en La invención de Atenas; en la importancia de la imagen en la monarquía absolutista del Rey Sol, expuesta e ilustrada por Peter Burke en La fabricación de Luis $X I V$; o, por supuesto, en el conocido y muy abundante uso de la propaganda totalitaria en el pasado siglo XX.

C. Geertz, Negara, op. cit., p. 28.

Ibidem, p. 181.

Ibidem, p. 30. Añade más adelante: "Los espectáculos ceremoniales no eran simples embellecimientos estéticos, celebraciones de una dominación que existían independientemente de ella: eran la cosa en sí misma” (p. 200). 
tología, y, al presentarla, hacer que ocurra, convertirla en real"6. Lo aparente, además de no ser un mero fenómeno que se explica desde unas realidades que permanecen invisibles a una mirada ingenua, es algo que puede atesorar un carácter performativo y de transformar la "realidad". De ahí su importancia y la necesidad de abordarlo desde su misma apariencia.

En Bali habría habido un tipo de poder que no puede ser reducido a factores como la fuerza, la coacción, la dominación o la violencia. Ante un tipo de poder, de hecho, en el que estos elementos no comparecen como sus rasgos principales, con lo que fenómenos como el esplendor y el prestigio, asociados a un poder simbólico y particularmente "poderoso" en su visibilidad, adquieren un mayor relieve en esta relectura antropológica del poder. De ahí que Geertz prefiera hablar de un "poder estético" o un "poder expresivo" donde la imagen cuenta mucho más que lo que supuestamente la sostiene. A decir verdad, el antropólogo estadounidense llega a insinuar que el ascenso en la pirámide del poder puede ir asociado a la pérdida de su poder de dominación. Es lo que llama la paradoja del negara: cuanto más cerca estaba alguien de encarnar la imagen del poder, más grande tendía a ser la distancia respecto a la maquinaria que controlaba ese poder ${ }^{7}$. En verdad, empero, Geertz no elimina el poder, lo desdobla y distingue dos circuitos por los que transita, donde uno se asocia al estatus, la jerarquía o el rango y el otro a la dominación; donde el que ostenta uno no tiene por qué detentar el otro y viceversa ${ }^{8}$. Además, eso no excluye que la violencia también pueda estar presente en la esfera ceremonial, como una violencia expresiva que se da por ejemplo bajo la forma de sacrificios celebrados por la población o de suicidios reales ${ }^{9}$.

Una exposición como la anterior no puede dejar de ser blanco de dudas, recelos, sospechas y preguntas como las siguientes. ¿Acaso Geertz no olvida algo fundamental en su descripción? ¿No habría un poder material o físico escondido detrás de toda esa trama ceremonial? ¿No habrá entendido Geertz lo cultural de una manera ingenua y al margen de unas luchas de poder que, desde fuera, no se presentan como tales? ¿Y no habrá caído en una lectura exotizante, orientalista y, en definitiva, etnocéntrica de la sociedad balinesa? Los interrogantes persisten hoy en día y buena parte de las críticas que recibió iban por esa línea y, entre otras cosas, le reprochaban haber caído en una postura idealista. Frente a este tipo de posiciones, representadas por los comentarios críticos de Talal Asad, Geertz respondió que caían en un reduccionismo del $\operatorname{poder}^{10}$. En su opinión, el problema radicaba en que los fenómenos sociales se

\footnotetext{
Ibidem, p. 183.

Ibidem, p. 229. En otro momento añade: "En aparente paradoja, toda la estructura se basaba primariamente en la ceremonia y en el prestigio, convirtiéndose el dominio político real de los reinos en más frágil y tenue a medida que uno ascendía en la pirámide; esta constatación evoca el símil del castillo de naipes, levantado fila por fila hasta su temblorosa cima" (p. 32).

8 Cf. por ejemplo lo que Geertz expone acerca del colectivo de los sudras y el de los brahmanas: "Aunque los sudras no podían convertirse en señores, príncipes o reyes propiamente dichos — dadas sus incapacidades de nacimiento, no podían ser figuras verdaderamente ejemplares-, sí podían representar papeles centrales en la política supralocal, y un cierto número de ellos así lo hizo. En el otro extremo, y con unas pocas excepciones cuidadosamente delimitadas, se excluía sistemáticamente a los brahmanas del acceso a la ejecución concreta del mando -y ello pese a que eran los únicos susceptibles de ser elegidos para el estatus más prestigioso de la cultura balinesa dejando aparte la realeza, el de sacerdote de Siva o padanda (Ibidem, p. 51)”.

10 A. Micheelsen y C. Geertz, “«I don’t do Systems»: an Interview with Clifford Geertz”, en Method \& Theory in the Study of Religion 14, 2002, pp. 2-20, aquí pp. 2-3.
}

$9 \quad$ Ibidem, p. 177. 
pensaban y explicaban prioritaria e incluso exclusivamente desde la perspectiva del poder, lo que conducía a desplazar el objeto de análisis en cuestión y a un nuevo simplismo que olvidaba o ninguneaba las singularidades de los fenómenos a analizar. Al entenderse todo dato cultural como una manifestación más del poder, lo que se hacía era igualar fenómenos que podían ser asaz diferentes entre sí e incluso inconmensurables. En cambio, el ejercicio planteado por Geertz en Negara puede ser interpretado como una arriesgada apuesta que se contrapone a esas tendencias de pensamiento, como las de raigambre foucaultiana aunque no solamente estas, que postulan la ubicuidad del poder. Y con ello lo que hace es desafiar nuestro sentido común, quién sabe si nuestros prejuicios, por ser incapaces de proponer una explicación del funcionamiento de una sociedad cualquiera que no se apoye en la decisiva presencia y centralidad de un poder cuando menos coercitivo. Al mismo tiempo, lo que hace es impugnar el punto de vista marxista, pues invierte la relación clásica entre estructura y superestructura. Paradójicamente, para ello no renuncia al término «poder», sino que lo redefine desde una perspectiva irreconocible para los representantes de esas tendencias mencionadas.

Compartidas o no sus observaciones, no dejan de suscitar preguntas como las siguientes: ¿Podemos pensar más allá del simple marco del poder? ${ }^{11}$ ¿Somos ingenuos por no ser capaces de divisar el poder que se esconde detrás de las manifestaciones culturales o lo somos por no ver nada más que poder? ¿Podemos imaginarlo o concebirlo desde una perspectiva simbólica desprovista de componentes coercitivos o violentos o donde estos ocupen un rol secundario? Y si no podemos, ¿cómo se puede entender alternativamente el concepto de poder para que sea capaz de explicar el desarrollo de una sociedad como la balinesa de Geertz?

Aquí es donde las reflexiones de Lefort entran en juego. Su noción de poder no deniega la existencia de componentes violentos y coercitivos del poder (en verdad el poco ingenuo Geertz tampoco) y no llega a desarrollar un escenario tan extremo como el de Negara, pero sí que abre el concepto de poder hacia una dimensión que conecta con los aspectos estéticos y simbólicos resaltados por el antropólogo estadounidense y ayuda a comprenderlos. En su opinión la dimensión simbólica no ocupa un rol secundario ni se reduce a uno instrumental.

\section{Claude Lefort y la dimensión simbólica del poder}

Es probable que Lefort nunca leyera Negara. Por lo menos no hemos encontrado alusiones suyas sobre el libro. Eso no impide que el texto de Geertz, debido a su radicalidad, pueda servirnos como una buena introducción a la comprensión lefortiana del poder. En consonancia con el antropólogo norteamericano, lo que se percibe en el autor francés es el esfuerzo por confrontarse con el poder más allá de su identificación o confusión con fenómenos considerados próximos, tales como la violencia, la fuerza, la coacción o la dominación. No se trata de que estos sean incompatibles con la existencia del poder, como el mismo Lefort mostró en sus abundantes escritos sobre el fenómeno totalitario, sino de que estas palabras no agotan el cúmulo de

En este sentido, puede ser de interés tener en cuenta que el historiador Richard J. Evans, en su reciente libro $L a$ lucha por el poder, sostiene que la obsesión por lo que ahora entendemos por poder es un fenómeno reciente y que no fue hasta el siglo XIX cuando pasó a estar por delante de otros valores como la gloria y el honor. 
matices que se esconden detrás de él y de que un exceso de énfasis en estos puntos puede llevarnos a olvidar otros rasgos suyos que no son menos importantes. Por seguir los términos de Arendt, una autora a la que Lefort apreció mucho y llegó a considerar como la más cercana a su manera de pensar ${ }^{12}$, se podría decir que un poder exclusivamente fundado sobre la violencia no se caracteriza por su potencia sino más bien por su impotencia: la impotencia de no lograr la obediencia más que bajo la condición de ser el resultado de unos actos de violencia o de coacción. De ahí que la lectura lefortiana del poder pueda ser entendida desde cierta perspectiva como la búsqueda de un poder más allá del poder.

Frente a esas visiones que tienden a restringir la descripción del poder a su componente violento, bien sea en su forma más latente o en su forma más patente, en su forma más sutil o más evidente, en su dimensión más simbólica o más física, Lefort reivindica el carácter y la primacía simbólica del poder. Y lo hace en un sentido que no deja de tener puntos en común con la noción de "poder simbólico" de Pierre Bourdieu $^{13}$, pero desde un prisma que es más político que sociológico. Para Lefort, el poder está ligado a un carácter representativo que ha tendido a ser pasado por alto $^{14}$ y por ello conecta directamente con una dimensión estética o con un régimen de visibilidad.

Para empezar, se debe ir con cuidado con el término "representación" porque no se debe restringir su significado a lo que se identifica con lo parlamentario, a la forma de gobierno más propia de la democracia representativa, sino que hace referencia a ese sentido previo que designa todo ese complejo y a menudo heteróclito conjunto de elementos que de algún modo y desde diferentes tipos de lenguajes, formatos y soportes representan a la sociedad y le otorgan una visibilidad. Se trata de una esfera que, debido a la habitual identificación de la representación política con el parlamentarismo, ha sido con frecuencia descuidada. La pregunta que se deriva de ello es hasta qué punto una sociedad política puede existir al margen de la esfera de la representación. Más aún, cómo la respuesta a esta cuestión afecta en la actualidad a esos movimientos, como el de los “indignados” en España, que, identificándola con la parlamentaria, han intentado concebir la democracia más allá de la representación ${ }^{15}$. ¿Es posible que el poder pueda prescindir de esta dimensión?

Por otro lado, frente a las interpretaciones reduccionistas del poder, Lefort acerca la comprensión de este término a algunos de los elementos que antes se situaban dentro de la esfera de la autoridad o, por decirlo en esa acepción romana cuya filiación se recuerda a menudo, la auctoritas. Así lo hizo ya Carl Schmitt, para quien la autoridad, como de manera ejemplar sucedía en el caso de la Iglesia católica, debía ser entendida en conexión con la representación ${ }^{16}$. Y se debe tener en cuenta cómo esa autoridad no puede ser analizada únicamente en términos de poder y mucho me-

12 C. Lefort, La complication: retour sur le communisme, París, Fayard, 1999, p. 17.

13 Cf. por ejemplo P. Bourdieu, Langage et pouvoir symbolique, París, Fayard, 2002.

14 Una excepción parcial sería Carl Schmitt y el análisis del poder que realiza desde la representación en Catolicismo romano y forma política.

15 Para una introducción al conflicto entre los indignados y la democracia representativa, cf. I. Gutiérrez (ed.), $L a$ democracia indignada: tensiones entre voluntad popular y representación política, Granada, Comares, 2014.

16 C. Schmitt, Catolicismo romano y forma politica, Madrid, Tecnos, 2011. En el español Diccionario de autoridades de 1726 aún se define la autoridad como "exceléncia, representación, estimación adquirida, ò por la rectitúd de la vida y eminéncia de la virtúd, ò por lo respetable de la nobléza y de la edad, ò por lo grande de la sabiduría, poderío, honór y otros títulos que hacen à uno digno de singular atención". 
nos de violencia; o, de hecho, cómo incluso un recurso de esta institución al poder y a la violencia puede damnificar o desautorizar a esa autoridad. La famosa anécdota en la que Stalin le pregunta en 1935 a Pierre Laval cuántas divisiones tiene el Papa, como si el poder se redujera a eso, es la que involuntariamente da pistas sobre esta cuestión y muestra la incapacidad del jerarca ruso a la hora de comprender los otros rostros de la autoridad.

Para Lefort, el poder no se define únicamente desde el lenguaje y el marco de la dominación ${ }^{17}$. En su opinión, el poder aparece asimismo como una compleja y no siempre diáfana instancia de legitimidad que al mismo tiempo también lo es de reflexión, de representación y de identidad; todos ellos elementos que en principio no forman parte de la violencia pero que de todos modos pueden estar atravesados por las diferentes y múltiples caras de ella. El poder, lejos de ser un fenómeno simple, mudo y aislado, consiste en una realidad compleja en la que hacen acto de presencia muchos otros elementos que se vinculan y/o anudan con su visibilidad, con su razón de ser o con su inteligibilidad. Según Lefort, puede ser descrito con extrema concisión como aquella institución que otorga a un grupo social su carácter de grupo político ${ }^{18}$, con las numerosas implicaciones que de todo ello se derivan. El poder, añade a continuación, es el lugar desde donde una comunidad se hace ver, leer y nombrar. Se trata de un rasgo crucial, puesto que el poder, al menos en la medida en que es político, demanda que haya un régimen de visibilidad al cual los miembros de una comunidad pueden apelar, en el cual pueden sentirse representados desde un punto de vista pragmático y cuyos símbolos, como en el caso de las banderas, pueden exhibir y empuñar. En este sentido, el poder comparece como una suerte de testimonio público (mas no inmediato ni necesariamente democrático) de la sociedad. Por ello, ambas dimensiones, las digamos física y simbólica, se hallan estrechamente entreveradas y no pueden ser separadas con facilidad. De manera semejante a la Negara de Geertz, según Lefort, el poder tiene que ver con algo estético que es "identificable por ese signo que todos los miembros de un grupo pueden nombrar"19. Poco después añade el pensador francés que el poder está ligado al imperativo de una puesta en escena que todavía perdura en los tiempos democráticos y precisa la presencia de elementos como los ceremoniales o la etiqueta ${ }^{20}$.

Para su relectura del poder, Lefort se apoyó no tanto en la teoría política como en sus lecturas antropológicas. Los textos de Maurice Hocart, como el todavía no traducido al castellano Reyes y cortesanos, y ante todo los de su amigo Pierre Clastres, como La sociedad contra el Estado, fueron importantes referencias para el desarrollo de sus reflexiones ${ }^{21}$. Los dos antropólogos retratan sociedades donde los poderes simbólico y ejecutivo están separados y donde el puesto del jefe queda preferentemente asociado al primero de ellos. Según Clastres, el poder de la jefatura (chefferie) se levanta sobre el rechazo de su poder coercitivo y eso conduce, por ejemplo, a que

\footnotetext{
C. Lefort, La complication, op. cit., p. 187.

C. Lefort, La incertidumbre democrática: ensayos sobre lo político, Rubí, Anthropos, 2004, p. 25.

Ibidem, p. 25.

$20 \quad$ Ibidem, p. 25. Que haya otros componentes más allá de los estéticos y que haya poderes en la sombra, no significa ni mucho menos que la dimensión simbólica no sea indispensable para todos ellos. Numerosas sociedades secretas, como la masonería, serían un buen ejemplo de ello.

$21 \quad$ No se trata de una casualidad, pues los antropólogos han resaltado con frecuencia el vínculo entre el poder y la representación. Marc Abélès ha señalado, por ejemplo, que para los profesionales de este campo los dos conceptos "son dos caras de una misma realidad". Anthropologie de l'État, París, Armand Colin, 1990, p. 100.
} 
a este jefe se le conceda el monopolio de la palabra y al mismo tiempo que esta no pueda ser una palabra de mando y a que su discurso "sólo será escuchado cuando exprese el punto de vista de la sociedad como totalidad"22. En la obra de ambos antropólogos se intuye la posibilidad de captar una dualidad dentro del concepto de poder que ya se había visto en el análisis de Geertz. En este sentido llega a escribir el antropólogo francés:

El poder político como coerción (o como relación de orden-obediencia) no es el modelo de poder verdadero, sino simplemente un caso particular, una realización concreta del poder político en ciertas culturas, como la occidental por ejemplo (que naturalmente no es la única). No existe pues ninguna razón científica para privilegiar esta modalidad del poder, para constituirla en el punto de referencia y en el principio de explicación de otras modalidades diferentes ${ }^{23}$.

Por otra parte, Lefort también subraya que el fenómeno del poder se asocia a la cuestión de la institución de lo social ${ }^{24}$. De entrada, eso significa que el poder no es solo un concepto encerrado en un ámbito reservado a los profesionales de la política y que toda sociedad, en la medida en que es propiamente política, se encuentra atravesada de forma persistente por la amenaza de la división. Lefort insiste en que la sociedad puede ser entendida como una unidad en conflicto, pero por eso mismo también acentúa que ella se confronta de manera insistente con la contingencia de su organización y, a su vez, con la aspiración e incluso la exigencia a querer borrarla ${ }^{25}$. Por eso, conviene entender el poder como una instancia que se esfuerza por alcanzar esa representación, esa legitimidad y esa inteligibilidad, pero que no lo suele lograr de manera plena y que a menudo está en disputa. La misma tendencia a la división, pertinazmente presente en toda sociedad, genera estrategias para remediarla o maniobras para enmascararla. De ahí que Lefort subraye que el poder se encuentre atrapado en la búsqueda incesante de su legitimación ${ }^{26}$ y persevere en intentar aparecer de una manera diferente, como algo más sólido, estable, permanente e incluso como algo imperecedero, natural o necesario, donde lo descriptivo se mezcla sutilmente con lo prescriptivo y le suministra un carácter fundante. En palabras de Lefort: la sociedad "se ocupa siempre de darse razón de lo que es: lo que es ha de ser como debe ser" 27 . Para ello, la apelación instrumental al pasado, tanto a nivel discursivo como estético, no deja de ser una estrategia recurrente. Ahora bien, lo que todo eso revela al mismo tiempo es que, en rigor, el poder no es ni puede ser soberano: detrás de las aportaciones de Jean Bodin y Thomas Hobbes sobre el concepto de soberanía se esconde la ilusión de un poder que pretende ser supremo, único, indivisible e incluso indisputable, un esquema que no tiene cabida en Lefort.

La sociedad, según el autor francés, se encuentra ante la necesidad de afirmarse y reafirmarse a sí misma de forma insistente, ante el requerimiento de mostrar como real y consistente esa ficción que presenta y representa. El poder aparece de este modo como un agente de presentación, representación y cohesión al mismo tiempo,

\footnotetext{
22 P. Clastres, Investigaciones en antropología política, Barcelona, Gedisa, 1981, p. 114.

23 P. Clastres, La sociedad contra el estado, Barcelona, Virus, 2010, p. 21.

24 C. Lefort, La incertidumbre democrática, op. cit., p. 26.

Ibidem, p. 26.

C. Lefort, Le Temps présent: écrits 1945-2005, París, Belin, 2007, p. 613.

27 C. Lefort, La incertidumbre democrática, op. cit., p. 26.
} 
como uno de afirmación y refuerzo simbólico, como un elemento de inteligibilidad y continuidad de la misma sociedad que muestra y escenifica públicamente la comprensión que "ella" tiene de sí misma. Desde este prisma, el poder no se caracteriza únicamente por la dominación de unos sobre otros, sino por tener la capacidad de generar una sensación compartida de unidad y de comunidad. De ahí que Lefort comente que el poder es "esa institución que da a un grupo social su carácter de grupo político" 28 . Y con el fin de instituir las condiciones de su inteligibilidad y proveer esta representación de sí misma, en este proceso impulsa un triple proceso que Lefort resume con las expresiones de "dar forma" (mise en forme), "dar sentido" (mise en sens) y "poner en escena" (mise en scène) las relaciones sociales ${ }^{29}$. El rasgo distintivo del poder, en contraste con la violencia o la dominación, se sitúa en vehicular y transparentar un modelo concreto de organización social.

En opinión de Lefort, cada forma política ha tratado de respaldarse sobre una dimensión simbólica, en especial un totalitarismo que ha sido el cultor paradigmático de una sagrada y férrea fantasía de la unidad. Por ello, el planteamiento lefortiano nos lleva a interrogarnos si es posible o concebible la existencia de un poder que no cultive su dimensión simbólica o, también, uno que sea puramente irracional o uno políticamente mudo, uno carente de todo carácter discursivo y sostenido nada más que sobre la violencia o la coerción. Frente a ello, en Lefort, se percibe cómo el poder trata de sustentarse sobre algún logos, cómo intenta explicarse de algún modo para sí mismo y sus súbditos o también para los demás, no importa en este caso si uno fingido, confeccionado artificialmente para exhibirlo como un vehículo más de propaganda o uno más sincero que contribuye a la comprensión del poder de sí mismo. Es probable que a menudo ambos aspectos se crucen y entremezclen. Al mismo tiempo, conviene tener en cuenta que esta dimensión simbólica no puede ser moldeada ad libitum por quienes están en el gobierno: en buena medida es el resultado de una compleja trabazón en la que intervienen numerosos elementos y donde lo discursivo y lo estético se entrecruzan. Además, esa dimensión simbólica puede generar efectos performativos, por lo que la misma representación no puede ser sólo entendida como una simple y fácilmente modificable representación. El mismo gobierno queda en buena medida atado a esa representación que pone en escena y pasa a ser juzgado y criticado desde ella ${ }^{30}$.

Así pues, de acuerdo con el esquema de Lefort el poder sobresale por su carácter exorbitante. Todo poder tiene cierto carácter trascendente, hace referencia a un "adentro" y un "afuera", los cuales están en relación y en tensión. Paradójicamente, y este punto es crucial, Lefort comenta que el poder apunta hacia un afuera a partir del cual se define a sí mismo ${ }^{31} \mathrm{y}$, como veremos, es esta relación de exterioridad la que a su vez puede ser impugnada. De ahí que haya que tener mucho cuidado con

\footnotetext{
Ibidem, p. 25.

Ibidem, p. 59.

30 Como ejemplo de la importancia que se le puede otorgar a los símbolos, y no solo por parte de los súbditos sino también de los gobernantes, recuérdese cómo Enrique V, el conde de Chambord, no pudo ser rey de Francia en 1871 por no querer aceptar la bandera tricolor y empeñarse en que lo fuera la insignia de los Borbones. Como contraste, el Papa Pío IX lamentó su reacción y al respecto comentó con acritud: "Enrique IV dijo que París bien valía una misa, a Enrique V le parece que Francia no vale ni una servilleta" (M. Burleigh, Poder terrenal: religión y política en Europa, de la Revolución Francesa a la Primera Guerra Mundial, Madrid, Taurus, 2005, p. 388).

31 C. Lefort, La incertidumbre democrática, op. cit., p. 67.
} 
qué imágenes o discursos se cultiven. A continuación agrega Lefort sobre el poder que

en todas sus formas nos remite siempre al mismo enigma: el de una articulación interior-exterior, el de una división que instituye el espacio común, el de una ruptura que simultáneamente es un poner en relación, el de un movimiento de lo social que es uno con el de su interiorización ${ }^{32}$.

Hay determinadas personas o instituciones políticas que son las depositarias de este poder pero sus signos y su distancia, añade Lefort, también se muestran en otros aspectos visibles y conocidos por los miembros de la sociedad: los mitos, las leyendas, los monumentos, los rituales, las procesiones, los ceremoniales y, por supuesto, un elemento tan relevante, y un espacio asimismo tan politizado y disputado, como la memoria colectiva de la comunidad. Con todo ello se evidencia que el poder acaba por estar ampliamente presente por los diferentes ámbitos de la sociedad ${ }^{33}$.

Como se comprueba en el pasaje citado más arriba, el poder alude a una ficción unitaria, pronunciada generalmente en singular, cuya realidad no deja de ser plural, contradictoria y conflictiva. Su dimensión simbólica y representativa no deja de ser problemática y, pese a tener lugar en un espacio asimétrico, este poder no puede ser nunca del todo determinable ni dominable. Por ejemplo, cada discurso puede ser contradicho por un discurso alternativo, cada memoria puede verse desafiada por una contramemoria o cada ceremonial puede ser ridiculizado por una parodia suya. El poder simboliza una sociedad que porfía por comprenderse y representarse a sí misma, que abriga el propósito de hacerlo más allá del conflicto, de la disensión y de la división social que en opinión de Lefort sacuden y desgarran a toda comunidad, pero de todos modos no logra hacerlo. Para este autor, al fin y al cabo, "la política" (la politique) no puede estar desligada de "lo político" (le politique), de ese componente conflictivo y divisorio. El mismo poder no deja de ser inestable y de ser cuestionado, razón por la que no puede operar nunca como si fuera nada más que un simple órgano o instrumento de las voluntades de un grupo o unas personas en concreto. Al manifestarse en el terreno de las apariencias y desplegarse bajo la forma de discursos puede ser comprendido y por ello despertar adhesiones, pero también puede ser respondido, puesto en cuestión o desafiado por esa población a la que dice o pretende representar simbólicamente. Al mismo tiempo, ese poder puede ser criticado por ser inconsecuente y no cuadrar lo escenificado con lo que es sentido como lo real: en estos casos, lo que se denuncia no es el logos del poder sino que este logos no sea más que un acto de hipocresía o una suerte de flatus vocis o palabrería vacía que no coincide con su actuación práctica.

El poder se encuentra anclado en una situación perenne de conflicto, sea uno tácito y tapado o uno abierto y explícito, y nunca puede encerrarse verdaderamente dentro de los márgenes de una representación determinada. Debido al mismo carác-

$32 \quad$ Ibidem, p. 67-68.

33 Uno de los mejores ejemplos del cultivo de esta unidad ilusoria se dio con las fiestas revolucionarias, bien estudiadas por Mona Ozouf en el contexto de la Revolución Francesa. En estas celebraciones se constataba tozudamente que la gozosa celebración de una unanimidad en teoría en concordia y armonía, de una unidad en la que también participaban mujeres y niños, no dejaba de estar atravesada por una pluralidad discordante y, ante su silenciamiento, de ser un acto de confirmación o de creación de nuevos excluidos y parias. M. Ozouf, La fête révolutionnaire: 1789-1799, París, Gallimard, 1989. 
ter dividido y plural de la sociedad, es imposible que ésta coincida de manera plena con la representación que se hace de ella. Toda sociedad acusa cierto desajuste en la esfera de la representación y revela con ello esa diferencia entre este afuera de la representación y este adentro en verdad irrepresentable. En el fondo, y de manera paradójica, el poder indica un lugar que al mismo tiempo que lo reafirma también descubre su limitación, revela lo que podríamos llamar su utopía, y desvela así su (relativa) impotencia. Eso explica que, con el objetivo de evitar conflictos que lo desgasten y debiliten, el poder dialogue, a menudo soterradamente, con una sociedad a la que dice representar y que se adapte parcialmente, en especial a nivel de discur$\mathrm{so}^{34}$, a los vaivenes de ésta. Esto es, la representación pasa a ser hasta cierto punto un diálogo o un juego de concesiones parciales entre los representantes oficiales, los representados y otras fuerzas que pueden ser externas. Al mismo tiempo que se presenta como director, el poder se muestra en estos contextos como algo hasta cierto punto dirigido, algo que no puede ser ni mucho menos unidireccional, unilateral o unívoco.

\section{Del poder del Antiguo Régimen al poder totalitario}

Un buen ejemplo del carácter exorbitante del poder se encuentra en los regímenes políticos que están marcados por la presencia de la religión y que recurren a ésta como su fuente de legitimación; aquellos que Lefort describe como los de matriz teológico-política. La representación de la sociedad se sitúa desde este prisma fuera de la misma sociedad, en un lugar no terrenal ni mundano, uno que al mismo tiempo que la escenifica y simboliza no deja de evidenciar su falta de coincidencia consigo misma. Recordemos por ejemplo cómo pueblos como el español o el inglés, durante la época moderna y a veces incluso en la bajomedieval, apelaron a las fuentes del Antiguo Testamento y realizaron maniobras para identificarse con el destino de los israelitas y presentarse así como una suerte de "pueblo elegido"35.

Al situar la fuente del poder en una instancia religiosa como la cristiana, la sociedad de los regímenes de matriz teológico-política se reúne y se define en relación con un ser divino que no es de este mundo y sobresale justamente por su carácter de

34 Pensemos por ejemplo en todos los ejercicios políticos realizados por regímenes dictatoriales a la hora de generar una ilusión de democracia o en las maniobras de pinkwashing, purplewashing, greenwashing e incluso redwashing que se han realizado. Un caso interesante es el de cómo el franquismo, en los años siguientes al fin de la Guerra Civil y con el fin de buscar un acercamiento discursivo a los partidarios del bando republicano, llegó a desarrollar una retórica populista espoleada por los miembros de Falange, cercana en no pocos puntos a la marxista y en la que el mismo Franco llegó a hablar en términos de "lucha de clases" (para esta cuestión, cf. C. Molinero, La captación de las masas: politica social y propaganda en el régimen franquista, Madrid, Cátedra, 2005).

35 Cf. A. Hastings, La construcción de las nacionalidades: etnicidad, religión y nacionalismo, Madrid, Cambridge University Press, 2000 y Ballester, Mateo, La identidad española en la Edad Moderna (1556-1665): discursos, símbolos y mitos, Madrid, Tecnos, 2010. Se trata de un gesto que el nacionalismo decimonónico imitará e intensificará, donde abundarán las estrategias de situarse como los descendientes de pueblos como los germanos, los celtas, los íberos, los eslavos o los romanos (cf. A. M. Thiesse, La creación de las identidades nacionales: Europa, siglos XVIII-XX, Madrid, Ézaro, 2010). Después de la Segunda Guerra Mundial, todavía el gobierno de Israel de David ben Gurion buscará como instancia de legitimación la de recurrir a las fuentes del Antiguo Testamento y la de generar un halo de continuidad entre el pueblo israelí contemporáneo y el israelita de las Sagradas Escrituras (cf. S. Sand, La invención del pueblo judio, Madrid, Akal, 2011). 
trascendencia. Este ser aparece como una entidad que confiere un sentido concreto a la comunidad y que también constituye su última fuente de legitimidad, pese a que al mismo tiempo no deje de comparecer asimismo como una alteridad radical, en este caso percibida como algo positivo. La sociedad, en consecuencia, se hace visible y se apoya en una trascendencia que le sirve de soporte y fundamento, pero con la cual no se identifica ni puede hacerlo de forma plena. Detrás del poder hay un exceso, un remanente que no se puede extirpar, y esta irreductible diferencia impide que la sociedad se pueda encerrar dentro de sí, sin poder esquivar la división de la sociedad y condenándola hacia cierto dinamismo, querido o no.

Entre estas formas políticas de matriz teológico-política descuella el ejemplo brindado por la monarquía de Luis XIV de Francia, cuyo reinado ha sido comúnmente descrito desde la ampliamente difundida y en verdad apócrifa expresión de "el Estado soy yo". En este caso, el poder está oficialmente incorporado o personificado en la figura del príncipe y su dimensión representativa habría sido posible porque esta persona no debe ser entendida exclusivamente desde una perspectiva individual. A nivel simbólico representa el cuerpo de la nación y la cabeza de la sociedad.

Para profundizar en esto, Lefort se adentra en los escritos de Ernst Kantorowicz y en su Los dos cuerpos del rey. Según este historiador, la figura del monarca medieval emulaba la de Jesucristo por el hecho de ser una gemina persona o poseer una suerte de doble naturaleza. Además de tener un cuerpo individual, biológico y mortal, aquel que es propiamente humano y finito, el rey, debido a la dignitas derivada de su cargo, también encarnaba el cuerpo colectivo e imperecedero de la nación; estaba investido de una dimensión numinosa que le servía para garantizar su integridad y que aparecía como el origen último de su legitimidad. Por extensión, la figura del rey se proyectaba sobre el espacio y el tiempo y destacaba por virtudes asociadas a su estatus como su clarividencia, su ubicuidad y su inmortalidad. La figura divina del rey, de un rex qui nunquam moritur o un roi qui ne meurt jamais, se contraponía a su cara más efímera y terrenal, con lo que escapa de la caducidad y limitación inherentes a los cuerpos humanos normales y se eleva por encima de la condición de sus súbditos. Por ello mismo, las capacidades que se le atribuyen están asimismo imbuidas de un carácter milagroso y, como estudió Marc Bloch ${ }^{36}$, se llegó a creer que monarcas como los franceses poseían un "tacto regio", un don por el cual podían curar a los súbditos de enfermedades como la escrófula. Bajo la sagrada imagen del rey, la sociedad se entiende así desde la figura de un cuerpo, un cuerpo que evoca la unión a la vez carnal y mística del rey con su nación, una metáfora corporal (o corporativa) que desde otros ángulos y con otros significados todavía sigue presente en la actualidad.

Sin embargo, este gobernante supuestamente absoluto tampoco es capaz de fundar su legitimidad sobre sí mismo. A decir verdad, estos monarcas aparecen como una suerte de mediadores entre el mundo visible y el terrenal que hallan su última fuente de legitimidad en Dios. Si bien el cuerpo del rey puede representar la nación entera gracias a estar impregnado de su carácter sagrado, es preciso agregar que esta sacralidad no la contiene en sí mismo de una manera plena. Ciertamente es un ser sagrado, pero al mismo tiempo no es más que un vicario de Dios, de un ser más sagrado y divino que él mismo, con lo que detrás de este movimiento se esconde una implícita admisión de cierta limitación y subordinación propias que también tendrán su correspondencia política.

36 M. Bloch, Los reyes taumaturgos, México, FCE, 1988. 
Para lograr una unión exitosa entre los dos cuerpos el monarca requiere la conexión con una divinidad y una religión que son tan trascendentes para la población como, en el fondo, para él mismo. La divinidad pasa a ser la fuente de su poder y de su autoridad. Al fin y al cabo, el monarca se presenta como un émulo de Cristo, un Christomimetes, alguien que tiene el deber de actuar a su imagen y semejanza. En este sentido, el historiador Paul Kleber Monod ha explicado cómo los monarcas modernos se esforzaron en practicar un "teatro de la virtud"37, lo que se plasmaba en que ellos quisieran encabezar las procesiones religiosas o ser retratados bajo simbología religiosa por los codiciados pintores de la corte del momento. Con ello, empero, se aceptaba implícitamente algo que se tendía a denegar explícitamente: la relevancia política del público hacia el cual iba dirigida esa teatralización.

Por un lado, se debe tener en cuenta que el mensaje cristiano y el ideal de ejemplaridad predicados resultaban incompatibles con la comisión de ciertas injusticias, arbitrariedades e inmoralidades, por lo que la fuente de poder podía llegar a convertirse en una fuente de contrapoder ${ }^{38}$. Eso explica que muchas revueltas modernas se hicieran en nombre de un cuerpo (la nación) y en contra de otro (el monarca como individuo). O que ya en la Edad Media se fuera consciente de la distinción entre el rey y la corona, con lo que el primero, como acaeció con Ricardo II de Inglaterra, podía ser acusado y depuesto por haber deshonrado a la segunda ${ }^{39}$. Dos siglos más tarde, como recuerda el mismo Kantorowicz, el grito de los puritanos en el contexto de la Revolución Inglesa no fue otro que el de "luchamos contra el rey para defender al Rey"40.

Por el otro lado, lo anterior explica también, como se plasma en los propósitos que animan la obra política de Bodin y Hobbes, las tentativas modernas de secularizar y hacer más inmanente y absoluta la fuente del poder, de hacerlo más firme y menos expuesto a los desórdenes y a los males de la guerra civil, algo que en la práctica no se llegó a conseguir del todo. Lo que es menos conocido y puede parecer a primera vista paradójico, algo diseccionado por el historiador Paolo Prodi en El soberano pontifice, es que esos procesos fueran justamente iniciados y capitaneados por un gobierno religioso como el de los Estados Pontificios ${ }^{41}$.

Lo que se puede inferir de esta breve incursión histórica es que el mismo absolutismo no puede alcanzar un poder que sea verdaderamente absoluto y que aquello a lo que apela como la fuente de su poder lo es a su vez de su limitación y, en algunos casos, de su posible derrocamiento futuro. De ahí que las maniobras de exhibición del poder, en la medida en que éstas persigan alcanzar la fidelidad de sus súbditos, también consistan en el simultáneo ocultamiento y en la tentativa de olvido de su verdadero origen. El objetivo no es otro que el de borrar la contingencia e incluso el carácter reciente y polémico de este origen y, con ello, del mismo poder en sí, intentándolo presentar bajo el aspecto de incuestionable y necesario. Esto será perseguido de nuevo en el seno de los regímenes totalitarios.

No obstante, Lefort destaca en primer lugar que la búsqueda totalitaria del poder y de la legitimación rompe con el de los regímenes de matriz teológico-política en

37 P. Kleber Monod, El poder de los reyes: monarquía y religión en Europa, 1589-1715, Madrid, Alianza, p. 109.

38 E. Straehle, "Between Power and Rebellion: Rethinking Authority", en Filosofia. Revista da Faculdade de Letras da Universidade do Porto 33, 2016, pp. 73-85.

39 E. Kantorowicz, Los dos cuerpos del rey: un estudio de teología política medieval, Tres Cantos, Akal, p. 366.

$40 \quad$ Ibidem, p. 52.

41 P. Prodi, El soberano pontifice: un cuerpo y dos almas. La monarquía papal en la primera edad moderna, Madrid, Akal, 2011. 
varios puntos. Frente a la apelación a la trascendencia de estos, el totalitarismo se refugia en una radical inmanencia, en lo que Lefort llama una ideología de granito que es extremadamente compacta y se presenta como totalmente cerrada ${ }^{42}$. Lo que se pretende suprimir en estos casos es el vínculo de dependencia con una instancia exterior e instaurar un gobierno completamente autosuficiente y autorreferencial. El totalitarismo habría comprendido que la apelación a una exterioridad como fuente de legitimación puede reforzar el poder pero que también lo limita y fragiliza de manera indirecta.

Por ello, el totalitarismo debe ser comprendido en relación e incluso como resultado del proceso de secularización en el que también se enmarca la democracia. Lefort apunta que su manera de comprender y de confrontarse con el poder no desciende del viejo esquema de las monarquías del antiguo régimen sino que surge como una reacción innovadora, y asimismo como una inversión radical, de la revolución democrática ${ }^{43}$, de la que hablaremos más adelante. Como la democracia, los regímenes totalitarios bajan a la tierra la fuente de su legitimación, pero no la colocan en un lugar vacío que expresa la centralidad y legitimidad del conflicto sino en un partido o una persona (como Hitler o Stalin) que la ocupan de manera individual, absoluta, avasalladora, indivisible y violenta. En su seno, además, se pretende que la dimensión simbólica de la sociedad pase a coincidir con la misma realidad de la sociedad, una realidad que pasa a estar encarnada por el partido y por el caudillo de turno. Por supuesto, la imagen de esa sociedad no es ya su plasmación real sino la oportuna ficción que se confecciona en su nombre. Lefort, tomando prestado un pasaje escrito por Trotski, comenta que Stalin se atreve a dar un paso más allá que Luis XIV y puede pronunciar con razón una frase como “¡la sociedad soy yo!”44. La consecuencia de esta personificación es convertir la pluralidad social en una pétrea unidad cuyo representante interviene como portavoz, funcionario y ejecutor de la sociedad a la vez. Lefort toma el término "egócrata" de Solzhenitsin para designar al dirigente totalitario ${ }^{45}$. En su opinión, éste ya no debe ser entendido como el tirano clásico que gobierna en solitario y en contra de las leyes, sino como aquel líder político que "concentra el poder social en su persona, y, así, aparece (y se aparece) como si nada hubiera fuera de sí mismo, como si hubiera absorbido la sustancia de la sociedad, como si, Ego absoluto, pudiera dilatarse infinitamente sin encontrar resistencia en las cosas"46.

El objetivo de los regímenes totalitarios consiste en tratar de liquidar el conflicto y la división que erosiona toda forma política y que caracteriza a la democracia. Se persigue la instauración de una sociedad que sea homogénea, unidimensional y plenamente coherente, que no tenga heterogeneidades, aristas ni resistencias, que activa una brutal y violenta lógica de la unificación y de la desdiferenciación y donde lo político es indistinguible de lo social. Retornando a la terminología corporal antes

42 Sobre la ideología de granito, escribe: "Se condensan las ideas en un discurso único, y éste ya no se mantiene a distancia de la sociedad a la que se supone que designa, se encarna en ella hasta ignorar su estatuto de discurso; ya no dictamina la verdad desde arriba, como el discurso burgués, ya no es discurso sobre lo social, sino discurso social" (C. Lefort, Un hombre que sobra: reflexiones sobre el Archipiélago Gulag, Barcelona, Tusquets, 1980, p. 178).

43 C. Lefort, La incertidumbre democrática, op. cit., p. 252.

44 Ibidem, p. 222.

45 C. Lefort, Un hombre que sobra, op. cit., p. 61.

46 Ibidem, p. 62. 
empleada, Lefort indica que lo que se produce en el totalitarismo puede ser entendido como un proceso de "incorporación". La sociedad queda incorporada en el Estado y pierde de este modo su especificidad y su diferencia. En el totalitarismo, la ideología del partido se infiltra en los numerosos campos de la vida cotidiana y tiene la pretensión de regularla hasta sus últimos detalles, inmiscuyéndose en ámbitos como la familia, las costumbres, la sexualidad, la educación, la literatura, el arte, la música o la ciencia. La coacción a los súbditos no se realiza únicamente desde afuera sino que penetra en la interioridad y en la conciencia de cada persona ${ }^{47}$. Y cualquiera que no se adapte a las pautas establecidas puede ser calificado de "parásito" o "enemigo del pueblo".

En contraste con la democracia, el totalitarismo persigue la fantasía de la soberanía y una suerte de fin de la historia y de la política, en la medida en que se obsesiona con la tarea de hacer desaparecer los conflictos y las tensiones que atraviesan la sociedad. Su propósito revolucionario, y de ahí también su terror inhumano, consiste en querer convertir en un hecho plenamente real y palpable la dimensión simbólica del poder. Paradójicamente, lo que logra en sus esfuerzos de liquidar «lo político» no es más que politizar todos los ámbitos de la vida cotidiana. Ninguno de estos puede ser considerado más como un espacio inocente o políticamente neutro.

Por esa razón, el régimen totalitario no cesa de contradecirse a nivel práctico. Más que neutralizar las divisiones y fundarse sobre una certeza sólida e indudable, lo que hace es llevar el conflicto a un nuevo terreno. En su seno, este no se da ya en el "adentro" de la sociedad sino que se dirime entre un "adentro" y un "afuera" en realidad ficticios, donde los diferentes, los disidentes o los inadaptados pasan a ser vilipendiados como traidores o enemigos de la patria y son confinados, expulsados de la sociedad, para formar parte de una alteridad sentida como amenazante y fantasmal. El totalitarismo, pues, no resuelve o disuelve el conflicto, lo expulsa de la "interioridad" de la sociedad y lo encara en la arena pública desde una imagen deliberadamente distorsionada o groseramente exagerada, cosa que fomenta la difusión de la paranoia y de las teorías de la conspiración. Curiosamente, lo que provoca en no pocos casos es sobredimensionar la importancia de los conflictos existentes, aunque como unos que al no reconocer como «internos» a la sociedad son afrontados en términos bélicos y respondidos a menudo con medidas brutales. En vez de enfocar la discrepancia de forma política y aceptar que la cuestión de la legitimidad está abierta, genera un abismo insalvable entre ambas posiciones, lo que lleva a la radicalización de las diferencias y a imposibilitar la reconciliación. A pesar de su obsesión por el conflicto, el totalitarismo vive en realidad de él, necesita su presencia inquietante y perturbadora para favorecer la cohesión de la sociedad y preservar la anhelada unidad. Por ello, habría que apuntar que la fuente del poder totalitario no solo procede de sí mismo, como pretende o llega a creer, sino que de forma indirecta y negativa, a contrario, también se alimenta de esa alteridad fantasmal que lo desafía y que aparece y presenta como su contraparte o negación.

Ahora bien, todo eso es lo que a la larga contribuye al ulterior desmoronamiento del totalitarismo. Lefort subraya la imposibilidad de precipitar lo simbólico sobre lo real ${ }^{48}$, de que desde el poder se pueda diseñar una sociedad y ahormarla a la doctrina predicada. El problema radica en que el totalitarismo confunde el poder con la fuerza

\footnotetext{
47 C. Lefort, ¿Qué es la burocracia?, París, Ruedo Ibérico, 1970, p. 129ss.

48 C. Lefort, La incertidumbre democrática, op. cit., p. 80.
} 
y la violencia y por ello acaba por ser el cómplice involuntario de su mismo hundimiento, un hundimiento que, como con la repentina caída del bloque comunista, puede provenir no de la violencia sino de otro tipo de poder como el «poder de los sin poder» tematizado por Vaclav $\mathrm{Have}^{49}$. Y es que en aquellas sociedades donde todo es político, los actos de desobediencia cotidianos pasan a tener una trascendencia política inédita e inquietante para los regímenes totalitarios. Así, la politización extrema que este hace de la sociedad se le gira en contra y acaba haciendo de él un poder desde cierto punto de vista débil y vulnerable, un poder en verdad desnudo que se aguanta mientras perdura la capacidad de disuasión y de intimidación de la violencia y donde toda discrepancia, al moverse en un terreno que el mismo totalitarismo ha convertido en político, gana una repercusión y, en fin, un poder que no tiene en otras formas políticas. Es el mismo exceso de política de un régimen que la intenta conjurar y su incapacidad de comprender las diferentes caras del poder lo que propicia su caída.

\section{El lugar del vacío del poder en la democracia}

Lefort insiste en que el carácter limitado y dividido del poder se percibe especialmente en el seno de la democracia. Esta forma política se le aparece de entrada como una nueva determinación o configuración del lugar del poder. Según Lefort, la democracia se caracteriza por ser una forma política que podríamos calificar de in-quieta $^{50}$, una que reconoce que la pluralidad, el conflicto y la desunión existen y que son insuperables. La democracia no persigue la instauración de la ilusión de una unidad fantasmagórica e inexistente, tampoco la presentada como la de una voluntad colectiva o la voz de un pueblo o una nación, pero no por ello erradica el poder ni tampoco se libera de la representación política. Frente a los partidarios de extirparla, el problema ya no se encontraría tanto en la persistencia de esta, una esfera a la que el mismo Lefort se refiere en cierto momento como indispensable, cuanto en desarrollar una comprensión y una articulación alternativa de ella. Democratizar la representación no sería lo mismo que parlamentalizarla mediante la elección de unos partidos y de unos representantes determinados bajo las condiciones de un sufragio universal. Al fin y al cabo, la primera pregunta que deberíamos formularnos es la de hasta qué punto la esfera parlamentaria representa en propiedad a una sociedad. En este sentido el pensador francés apunta que, entre otros, también los sindicatos, las asociaciones de diverso tipo y los movimientos sociales toman parte en esa representación pese a que su participación no esté legalmente reconocida ${ }^{51}$. En su opinión, una representación no puede ser fecunda, y democrática podríamos añadir,

si ella no viene a arraigarse en un suelo determinado, a inscribirse en un espacio social vivo, en el cual circula la información, en el cual las opiniones múltiples pueden expresarse, en el cual, en fin, puede haber para los grupos y los individuos

\footnotetext{
49 V. Havel, El poder de los sin poder. Madrid, Encuentro, 1990. Para una interpretación que cuestiona el rol de la disidencia y de la sociedad civil como causa central de la caída del bloque comunista, cf. S. Kotkin, Uncivil Society: 1989 and the Implosion of the Communist Establishment, Nueva York, Modern Library, 2009.

50 Para esta cuestión, cf. E. Straehle, Claude Lefort: la inquietud de la politica, Barcelona, Gedisa, 2017.

51 C. Lefort, Le temps présent, op. cit., p. 616-617.
} 
diferentes, una sensibilidad para aquellos intereses y aspiraciones que no sean los suyos. En resumen, la representación requiere el establecimiento de un espacio público tal que pueda efectuarse una modificación mutua de los puntos de vista y hacerse reconocer la legitimidad de los nuevos derechos por la opinión pública ${ }^{52}$.

La democracia, según Lefort, no suprime el poder. Lo que hace es bajarlo a la tierra, impersonalizarlo, inscribirlo dentro de la misma sociedad y con ello disociarlo del Estado ${ }^{53}$. Al contrario que en el totalitarismo, no se subordina el destino de la sociedad a la representación del poder sino que éste es por así decir democratizado y queda abierto a los vaivenes y conflictos de la sociedad. Bajo esta perspectiva, la simbólica ejecución de Luis XVI en el transcurso de la Revolución Francesa no solo tiene como resultado la supresión del poder monárquico y la proclamación de la república. Más importante, para Lefort este gesto deriva asimismo, cuando menos a nivel ideal, en la secularización del régimen político y en la eliminación del fundamento divino y trascendente del poder en sí. En lo sucesivo las justificaciones del poder deberán tener un carácter inmanente y proceder del mismo «pueblo» que el poder asegura representar. No obstante, que este poder esté en un proceso de secularización, no lo lleva a incardinarse en el rostro de otra persona singular, ficticia o no, personal o institucional, como intentó Hobbes en su modelo político y siguen buena parte de los planteamientos políticos que se cobijan en la noción de soberanía. Esto es lo que habría llevado a la creencia en la soberanía popular, donde la ilusión de la soberanía pervive bajo la condición de una teórica transferencia a un pueblo que delega con su voto en unas personas o instituciones a quienes reconoce como sus representantes. Frente a esto, lo que sucede es que aquello que se presentaba como la unidad del poder pasa a ser pluralizada y que el cuerpo colectivo de la comunidad pasa a representarse a sí mismo a través del conjunto del mismo pueblo. La democracia lleva el poder a un lugar vacío que, en la medida en que siga siendo democrático, no puede erradicar ni patrimonializar de ningún modo ${ }^{54}$.

Que el lugar del poder esté vacío no es lo mismo que decir que éste haya desaparecido o haya sido abolido. Ahora bien, lo importante es que ya no puede ser ocupado por una sola persona ni tampoco detentado por nadie bajo un régimen de propiedad. Lo que explosiona no es el poder sino su unidad. Y que este poder no pueda ser el monopolio de ninguna persona es lo que lo abre al conjunto de la sociedad y permite que por definición sea discutible y disputable. La disputa, que no es más que el efecto de la pluralidad, ya no es una anomalía ni algo a ocultar, sino la propia razón de ser de la democracia. Las tensiones inherentes al poder perduran, pero en lo sucesivo son estas tensiones, las continuas confrontaciones que se dan en la esfera de la representación, las que pueden e incluso deben ser mostradas y visibilizadas. Y se debe tener en cuenta que esta confrontación no se da tan sólo como una contienda digamos ideológica, pues va aparejada a las correspondientes luchas materiales y concretas.

Además, esta especie de vaciamiento del poder, en verdad su falta de substancia y desincorporación, significa que no hay ninguna instancia que pueda expresar o determinar qué es en propiedad la democracia. El poder, en esta forma política, es

Ibidem, p. 617.

C. Lefort, La incertidumbre democrática, op. cit., p. 74s.

54 C. Lefort, El pueblo y el poder, Buenos Aires, Prometeo Libros, 2014, p. 44. 
irrepresentable e infigurable ${ }^{55}$. Y en el caso de que sí lo fuera, sería como una unidad dividida que reflejaría y transparentaría los conflictos que de forma inevitable caracterizan a la política. En otras palabras, Lefort sostiene que solo este vacío puede convertirse en una instancia simbólica y que, por ello, lo que propiamente representa no es más que este mismo vacío, esta indeterminación y apertura radicales, esta división inevitable y esta pluralidad inerradicable. La democracia aparece así como esa forma política que, por el hecho de ser política, no es apropiable, reificable ni figurable. Si lo fuese, dejaría de ser una democracia.

Finalmente, lo que Lefort llama la "revolución democrática", expresión que toma prestada de Tocqueville, también aparece como el resultado de un proceso de separación o desimbricación de los órdenes o las instancias del poder, de la ley y del saber. $\mathrm{Si}$ antes se había intentado que las tres esferas permanecieran unidas bajo el mando de la primera, a partir de este momento se produce una separación que debe permitir la autonomización de las otras dos y su no subordinación a la del poder. La revolución democrática, pues, supone la pluralización de las fuentes de un poder que debe reconocer el conflicto como algo inevitable y también constitutivo, como el motor y excipiente de su mismo desarrollo democrático. A su vez, eso implica la separación de las instituciones de poder de la religión (su secularización y su laicidad), de la ley (la independencia de la esfera judicial) y del saber (la no injerencia en los campos de la ciencia y del conocimiento) como instrumentos de gobierno.

En conclusión, lo que Lefort entiende por democracia comparece como una forma política intrínsecamente aporética que se funda en la alianza de dos principios que no dejan de ser contradictorios: el primero, que el poder emana del pueblo; el segundo, que este poder no es de nadie ${ }^{56}$. La democracia se muestra como un régimen político cuyo fundamento, el pueblo, es en verdad una ausencia de fundamento. Debido a su carácter plural e imposible de ser reducido a una unidad, ese pueblo no se muestra más que como un cúmulo de divergencias, discrepancias o incluso de conflictos y de antagonismos. De ahí que Lefort defina la democracia como la institucionalización del conflicto ${ }^{57}$ y que deba estar permanentemente abierta al debate de qué es legítimo y qué ilegítimo, qué es justo y qué injusto, qué es verdadero y qué es falso, qué es legal y qué ilegal y, en fin, qué es democrático y qué no lo $\mathrm{es}^{58}$. Se trata, además, de una serie de debates sin garantía ni punto final. Ahora bien, esto no constituye por así decirlo un problema, sino su misma razón de ser. Que estos conflictos pudieran ser respondidos y resueltos de manera definitiva es lo que dictaminaría implícitamente la muerte de la democracia y la pérdida de su carácter propiamente político. Lejos de erradicar el poder, podríamos aseverar que en la democracia está más vivo y activo que nunca.

C. Lefort, La incertidumbre democrática, op. cit., p. 33.

C. Lefort, La invención democrática, Buenos Aires, Nueva Visión, 1990, p. 42.

C. Lefort, La incertidumbre democrática, op. cit., p. 47 y 69.

Ibidem, p. 34. 